\title{
One piece at a time: Making sense of chronic lung allograft dysfunction
}

\author{
Victor van Berkel, MD, PhD
}

\footnotetext{
From the Department of Cardiovascular and Thoracic Surgery, University of Louisville School of Medicine, Louisville, Ky.

Disclosures: Author has nothing to disclose with regard to commercial support.

Received for publication Feb 22, 2018; accepted for publication Feb 23, 2018; available ahead of print March 17 2018.

Address for reprints: Victor van Berkel, MD, PhD, 201 Abraham Flexner Way, Suite 1200, Louisville, KY 40202

(E-mail: victor.vanberkel@louisville.edu).

J Thorac Cardiovasc Surg 2018;155:2777-8

$0022-5223 / \$ 36.00$

Copyright (c) 2018 by The American Association for Thoracic Surgery

https://doi.org/10.1016/j.jtcvs.2018.02.059
}

Despite continued gradual improvement in both short-term and long-term survivals after lung transplant, long-term overall outcomes are substantially worse than those of other solid organ transplants. ${ }^{1}$ The predominant mechanism that leads to these poor outcomes is the development of chronic rejection. ${ }^{2}$ Initial histologic examination of lung tissue from transplant recipients with a decline in allograft function demonstrated changes of obliterative bronchiolitis, ${ }^{3}$ which was thought to be the dominant clinical manifestation of chronic rejection. Demonstration of obliterative bronchiolitis by means of bronchoscopic biopsy is challenging, however, and so in 1993 an International Society for Heart and Lung Transplantation committee introduced the term bronchiolitis obliterans syndrome (BOS) to reflect chronic respiratory decline thought to be due to the development of obliterative bronchiolitis. ${ }^{4}$ BOS was defined by strictly clinical parameters as a persistent obstructive decrease in forced expiratory volume in 1 second of at least $20 \%$ of the patient's best posttransplant values, with a grading system dependent on the degree of forced expiratory volume in 1 second loss.

With time, however, it became apparent that there was marked heterogeneity in the patients who fit the criteria of BOS, with distinct differences in progression of respiratory failure, radiographic appearance, and response to therapies. Recently, the term restrictive allograft syndrome (RAS) was coined to describe a novel subset of patients with chronic decline of pulmonary function. This syndrome was defined by clinical and radiographic parameters, specifically a restrictive defect with a greater than $10 \%$ decrease in total lung capacity with associated pleuroparenchymal infiltrates on chest computed tomography. ${ }^{5}$ Notably, patients with RAS have been found to have a significantly shorter postdiagnosis survival than patients with BOS.

With the advent of these clinically different groups, in 2014 International Society for Heart and Lung Transplantation established a new classification system for pulmonary function decline in patients after translplantation. ${ }^{6}$ A new

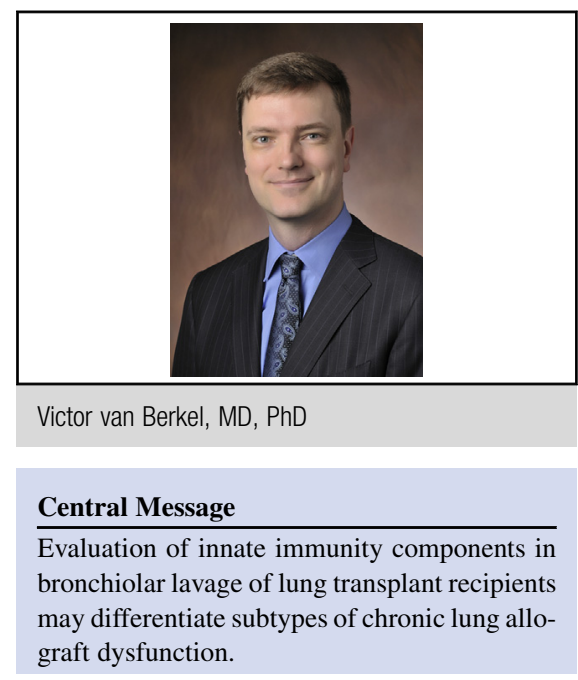

See Article page 2774. (CLAD), was defined as a persistent (at least 3 months) decline in pulmonary function (forced expiratory volume in 1 second or forced vital capacity) of greater than $10 \%$ from baseline. Under the new nomenclature, both BOS and RAS are considered subsets of CLAD.

Although the definition of these syndromes has helped classify patients with failing pulmonary transplants, more rigorous markers of these disease processes are needed for both clinical and scientific progress with these patients. In this issue of the Journal, Saito and colleagues ${ }^{7}$ describe an evaluation of bronchiolar lavage samples from transplant recipients in the absence of CLAD and in the presence of clinical BOS and RAS. They identify several components of the innate immune system that are elevated in the patients with CLAD and, crucially, 2 markers in particular (neutrophil elastase and long pentraxin 3 ) that are specifically elevated only in RAS.

Although this is clearly a pilot study and limited by small numbers, the results of Saito and colleagues ${ }^{7}$ suggest that there may be easily isolated biologic markers that would enable a more rigorous definition of CLAD subtypes. Not only would the discovery of such markers reduce the heterogeneity present in current studies defined by clinical syndromes, it could conceivably lead to the identification of patients at risk for development of these clinical syndromes before they are symptomatic, allowing proactive, rather than reactive, treatment. 


\section{References}

1. Opelz G, Döhler B, Ruhenstroth A, Cinca S, Unterrainer C, Stricker L, et al. The collaborative transplant study registry. Transplant Rev (Orlando). 2013; 27:43-5.

2. Yusen RD, Edwards LB, Dipchand AI, Goldfarb SB, Kucheryavaya AY, Levvey BJ, et al; International Society for Heart and Lung Transplantation. The registry of the International Society for Heart and Lung Transplantation: thirty-third adult lung and heart-lung transplant report-2016; focus theme: primary diagnostic indications for transplant. J Heart Lung Transplant. 2016;35: 1170-84.

3. Burke CM, Theodore J, Dawkins KD, Yousem SA, Blank N, Billingham ME, et al. Post-transplant obliterative bronchiolitis and other late lung sequelae in human heart-lung transplantation. Chest. 1984;86:824-9.
4. Cooper JD, Billingham M, Egan T, Hertz MI, Higenbottam T, Lynch J, et al. A working formulation for the standardization of nomenclature and for clinical staging of chronic dysfunction in lung allografts. International Society for Heart and Lung Transplantation. J Heart Lung Transplant. 1993;12:713-6.

5. Sato M, Waddell TK, Wagnetz U, Roberts HC, Hwang DM, Haroon A, et al. Restrictive allograft syndrome (RAS): a novel form of chronic lung allograft dysfunction. J Heart Lung Transplant. 2011;30:735-42.

6. Verleden GM, Raghu G, Meyer KC, Glanville AR, Corris P. A new classification system for chronic lung allograft dysfunction. J Heart Lung Transplant. 2014;33: 127-33.

7. Saito T, Liu M, Binnie M, Martinu T, Sato M, Keshavjee S. Upregulation of alveolar neutrophil enzymes and long pentraxin-3 in human chronic lung allograft dysfunction subtypes. J Thorac Cardiovasc Surg. 2018;155:2774-6. 